\title{
Understanding risk perception in travellers
}

\author{
Lorraine M Noble
}

Senior Lecturer in Clinical Communication

UCL Medical School, UCL, London, UK

\section{Contact details:}

Dr Lorraine Noble

UCL Medical School

Royal Free Hospital

London

NW3 2PF

Email lorraine.noble@ucl.ac.uk

This article is based on an invited lecture given at the Primary Care and Public Health conference, May 2016, Birmingham 


\begin{abstract}
Information is widely available about travel risks and prevention. Yet, every year a proportion of travellers are affected by illnesses or injuries sustained during their trip, many of which are preventable. In this article we will consider how people perceive risk; how people make decisions about engaging in preventative behaviour; and the role of the pre-travel consultation in promoting healthy behaviour in travellers. The article defines factors that affect travellers' choices about taking preventative measures and describes strategies to enhance the effectiveness of the pre-travel consultation.
\end{abstract}

\title{
Key points
}

- What matters in terms of activating preventative behaviour is whether the person feels that the risk applies to them and is sufficiently serious to warrant a response

- People make strategic and rational choices about what to do

- The aim of the patient-centred pre-travel consultation is to empower the individual to make the choices which best meet their needs

\section{Key words}

- Communication

- Consultation

- Travel health

- Risk perception

- Adherence 


\section{Understanding risk perception in travellers}

How can we ensure that travellers are protected as best they can be? Despite the ready availability of information, and many travellers attending for a pre-travel consultation, travellers often do not follow a preventative regimen which matches up with guidance. Every year a proportion of those (8\%) travelling to developing countries require medical intervention during or after their trip (Freedman et al 2006). Common forms of non-adherence to medication prophylaxis include forgetting, stopping due to side effects, stopping on return home and substituting remedies. Non-adherence to advice can be intentional or non-intentional, and many studies have shown that partial adherence is the most common response (Noble et al 2012, Noble 2014).

\section{Risk perception}

When we consider 'risk-taking behaviour', this often brings to mind activities we perceive as 'risky' such as bungee jumping or adventure sports. We are less likely to consider everyday activities, such as travelling by road, or activities deemed to be 'healthy', such as taking a walk in the great outdoors. In terms of risk to the individual, deaths due to road traffic accidents in the UK are more common than for perceived 'risky activities' (Office for National Statistics 2012). For example, taking a walk in moorland, grassland or forests results in 2000-3000 cases of Lyme disease annually in the UK (NHS Choices 2016).

When considering how travellers perceive risks, sometimes assumptions are made that:

- Everyone agrees what is risky or safe

- Activities which are risky should be avoided 
- Taking risks is not part of the fun

- People will take preventative action for all risks

- Staying safe and healthy is fully under an individual's control

- Nobody gambles with their health

- People follow all health and safety advice

There is considerable evidence that people - including travellers and health professionals - have different perceptions of risk, tolerance of risk and preferences for responding to risk (Noble et al 2012). For example, two common, but quite different approaches to risk are the 'precautionary approach' and the 'resilience approach'.

Following the precautionary approach, people will avoid an activity or situation that is suspected to cause harm, even in the absence of evidence that it does (e.g.

European Commission 2000). Examples include the European ban on British beef exports as a result of the BSE crisis; controversies over fluoridation of water in the USA; parental concerns about MMR vaccination; and the current debate about whether to impose a ban on e-cigarettes (e.g. World Health Organisation 2014). This approach could be summarised as 'prevention is better than cure'. Alternatively, following the resilience approach assumes that adverse events will happen at some point, even with the best preparation. Thus, the focus is on putting plans into place to reduce the likelihood or impact of the adverse event, and to respond effectively when needed. This involves four stages: readiness, mitigation, response and recovery. In these stages action is taken to anticipate problems, monitor potential risks (early warning system), prepare contingency plans, train and rehearse plans, and if adverse events happen, learn from the experience. Examples 
include aviation safety, preparation for pandemics and management of outbreaks of infectious disease on cruise ships.

It is often assumed that travellers will wish to follow the precautionary approach and take preventative measures for all the health risks that the health professional outlines. However, there is evidence that travellers may prefer the resilience approach. For example, Voumard and colleagues provided travellers planning to visit areas of low-to-moderate risk of malaria with written information about malaria prevention and asked for their preferred approach. Only 15\% chose chemoprophylaxis; $26 \%$ preferred to use bite prevention methods only and $59 \%$ preferred to use stand-by emergency treatment (Voumard et al 2015). The investigators concluded that: "For malaria prevention, the consumer's perspective has never been considered, which could explain the rather low adherence to the recommendations, especially to chemoprophylaxis."

\section{Health beliefs}

How do we predict how an individual person will respond to a risk? With regard to health risks, this involves the individual weighing up (Carpenter 2010):

- Their susceptibility to the threat: whether the risk applies to them in particular.

- The severity of the threat: how serious the consequences would be to them.

- Benefits and barriers to taking action: whether, on balance, the individual has more to gain from taking action than it costs (in terms of time, money, hassle).

- Self-efficacy: whether the person feels able to take the required action when it is needed.

- Cues to action: whether the behaviour is triggered when it is needed. 
Merely knowing that there is a risk is not sufficient, as people are exposed to risks every day and, generally, learn to live with them. What matters in terms of activating preventative behaviour is whether the person feels that the risk applies to them and is sufficiently serious to warrant a response. In a consultation, it can be helpful to check whether the person feels the risk is important to them and whether they feel that they are able to do something about it. For example, a traveller who knows that they will struggle to remember to take a tablet every day, or feels that they will be unable to ask a new sexual partner to wear a condom, may have accurate knowledge of risks, but this may not be sufficient to translate into preventative behaviour.

\section{Knowledge, health beliefs and behaviour}

Travellers often arrive at a pre-travel consultation with some knowledge of the likely health risks of travel and preferences about how to respond to these. So for example, a proportion of people believe that they have natural immunity to malaria, or have already had the vaccine for it, or feel they are not at risk due to the duration of the trip. There are a variety of views about whether prevention is needed or effective; e.g. if a person believes their health lies in the hands of fate or a deity, rather than being within the individual's control. Side effects often cause concern among travellers and patients in general, and worries about side effects may be more immediate than concern about the diseases they are intended to prevent. Travellers may also find themselves in situations where the risks are different to their normal experience. For example, a person who is a competent swimmer might not realise that there is a risk of drowning because they do not usually swim in the sea at 
night at a beach party whilst under the influence of alcohol, while everyone around them is also under the influence of alcohol.

\section{Influences on risk perception}

Beyond the individual's health beliefs, there are also other influences on risk perception. Cultural and social norms play a role. For example, if a person's family members never use preventative measures, the individual may perceive the risk as lower. Consistency of advice is also important. Travellers often access multiple sources of advice, including friends and family, the internet, travel agencies, and general practice and travel clinics - and advice changes over time and is often conflicting. Even national guidelines to certain destinations vary; for example, travellers to Cambodia from different countries might have received very different advice about malaria. This can lead to confusion among travellers about what preventative action needs to be taken, if any. The environment at the time preventative behaviour is needed can also affect perception of risk. If there is no form of transport other than by motorcycle at a destination, and everyone is travelling by motorcycle, this 'normalises' this form of transport as a routine behaviour.

Finally, there is the effect of a person's mood or mental state on their perception of risk - when people are happy, relaxed or excited, risks seem less prominent.

\section{Strategic decisions about taking preventative measures}

Becker (1985) noted that, in healthcare, we often assume that people who follow medical advice get better (if they are ill), or stay well (if it is preventative); and those who do not follow health advice, either don't get better or become unwell. However, he suggested that most adults have had sufficient experience of healthcare to know 
that sometimes people do not follow advice, and stay well, or do follow advice, but still become ill. Consequently, when faced with a threat to their health, people do not necessarily follow health advice, but instead, make strategic and rational choices about what to do. This includes non-adherence to health advice. In situations where there are may be risks to the traveller, but it cannot be known whether the traveller is likely to be affected, an honest discussion about this uncertainty enables the traveller to make an informed choice.

\section{The pre-travel consultation}

In the traditional pre-travel consultation, as presented in the Centers for Disease Control and Prevention CDC 'Yellow Book' (Chen et al 2016), there are two tasks. The first is to gather information from the traveller in order to assess the risks that they may be facing. The second is to manage the risk, by providing the traveller with information about what the risks are and advice on how to respond to these risks (Figure 1). This is what we would call a traditional 'sender-receiver' model of communication, where the aim of the conversation is an exchange of information, which flows firstly in one direction (traveller to health professional) and then in the opposite direction (health professional to traveller).

There is considerable evidence that information alone not enough to encourage people to adopt preventative behaviour. The person needs to be motivated in terms of seeing the value to themselves, and to judge that the benefits of taking action are worth the costs. The person also needs to feel confident that they have the skills to perform the behaviour when it is needed; essentially does the person feel that this is within their control? The Information-Motivation-Behavioral Skills model was 
developed by Fisher and Fisher (1992) to provide a framework to help understand the elements that are needed to promote preventative behaviours (Figure 2).

\section{Goals of the consultation}

Understanding how people choose to engage in preventative behaviours changes the goals of the pre-travel consultation. As well as providing information, the health professional aims to explore the individual's understanding of risk and encourage behaviour to respond to the risks (e.g. Fischhoff et al 2011). Using the traditional model of the pre-travel consultation, the health professional would explain to the traveller that there is a risk and give advice about preventative action to take. However, this does not necessarily engage with what the person is already thinking; for example: "I didn't take anti-malarials last time, and I was okay" or "I don't want to take the tablets with side effects" or "I'd rather wait and see, and I will get treated if I need to." Without an exchange of views, where each person in the conversation explicitly shares their perspective of risk and preferred responses to it, the professional may feel that their advice has been received, but the traveller may feel that it does not apply to their circumstances.

\section{The patient-centred approach}

The current frameworks of patient-centred care and shared decision making address this discrepancy, as the focus is on the patient and health professional working together to make a plan which meets the patient's individual needs, values and preferences (Coulter \& Collins 2011, Foot et al 2014). Crucially, it begs the question: is the aim to improve 'compliance' with advice, or to support the person in making the best decision for themselves? Professor David Haslam, the chair of the National 
Institute for Health and Care Excellence (NICE), recently emphasised that people "have to be at the centre of decisions with expert judgment from health professionals informed by expert guidance" (NICE 2016).

\section{The patient-centred pre-travel consultation}

Using this approach, the aim is to empower the individual to make the choices which best meet their needs (Figure 3 ). In the early stages of the consultation, the traveller's priorities and perspective are explored, and the traveller and health professional share their perceptions of risk and the pros and cons of the available options. This leads up to a final stage, where the traveller makes the decision, supported by the health professional (e.g. see Coulter \& Collins 2011, Elwyn 2015). In this consultation, the tasks incorporate the traveller's perspective and the health professional's perspective. There are certain elements of the process of communication which are known to improve the effectiveness of the consultation (Box 1) (e.g. Coulter \& Collins 2011, Noble et al 2012, Silverman et al 2013, Noble 2014).

\section{The changing nature of risks}

The nature of risk in travel medicine is also changing. Traditionally, health professionals and travellers have focused on infectious diseases which are preventable, either by medication or vaccines. However, deaths and serious injuries in travellers are most commonly caused by accidents (such as road traffic accidents) and violence (e.g. Zimmer 2012). Problems that are more likely to cause considerable disruption to a person's trip include traveller's diarrhoea and sunburn. Zimmerman and colleagues (2013) found that differences in travellers' and health 
professionals' perceptions of risks, with travellers rating the risks of accidents and sexually transmitted infections lower than professionals.

In order to make an informed decision about taking preventative action, individuals can reasonably expect to be provided with information about how likely a risk is. In many areas of medicine, evidence-based information about risks is being used to develop patient information resources to help with decision-making (e.g. Forbes et al 2014). However, the likelihood of risks is often unknown in travel medicine. This makes it very difficult for travellers to assess the first component in the process of decision-making, i.e. their susceptibility to the health threat. This inherent uncertainty is an important part of the conversation.

Spiegelhalter and Riesch (2008) noted that:

"Advising the public on their behaviour is an intervention that is not cost-free - every time advice is given and ignored it may make it more difficult to promote future recommendations."

Travel medicine also reflects trends in population health. The UK population is ageing, with increasing numbers of people living with multiple and chronic conditions, and this is changing the nature of healthcare consultations (Noble 2016). The effects of a trip on pre-existing medical conditions, such as disruption to selfmanagement routines, can be expected to play an increasing role in the assessment of health risks to travellers.

Furthermore, there are new risks coming to light which will affect judgements about priorities when considering the health risks posed by a trip. For example, the Department of Health has recently published recommendations on safeguarding women and girls at risk of female genital mutilation when travelling to visit families or their countries of origin (Department of Health 2015). For some travellers, the 
traditional categories of travel health risks may inadequately reflect the risks that they face.

\section{Conclusions}

People, including health professionals and travellers, vary in their perception of risk, tolerance to risk, and preferred responses to risk. Consultations that are dynamic, in which participants share their perspectives, encourage understanding and improve discussions about risk. Health professionals play a vital role in supporting travellers in selecting a course of action which best meets their needs. 


\section{References}

Becker MH (1985) Patient adherence to prescribed therapies. Medical Care 23(5):539-55

Carpenter CJ (2010) A meta-analysis of the effectiveness of health belief model variables in predicting behavior. Health Communication 25(8):661-9

Chen LH, Hochberg NS, Magill AJ (2016) The pre-travel consultation. CDC Health Information for International Travel wwwnc.cdc.gov/travel/yellowbook/2016/the-pretravel-consultation/the-pre-travel-consultation (accessed 20 June 2016)

Coulter A, Collins A (2011) Making shared decision-making a reality: no decision about me, without me. King's Fund, London.

Elwyn G (2015) Collaboration talk model for shared decision making.

www.glynelwyn.com/blog/collaboration-talk-model-for-shared-decision-making (accessed 20 June 2016)

Department of Health (2015) Safeguarding women and girls at risk of FGM. https://www.gov.uk/government/publications/safeguarding-women-and-girls-at-riskof-fgm (accessed 20 June 2016)

European Commission (2000) Commission adopts communication on precautionary principle. http://europa.eu/rapid/press-release_IP-00-96_en.htm (accessed 20 June 2016)

Fischhoff B, Brewer NT, Downs JS (eds) (2011) Communicating risks and benefits: an evidence based user's guide. Food and Drug Administration (FDA), US Department of Health and Human Services www.fda.gov/downloads/AboutFDA/ReportsManualsForms/Reports/UCM268069.pdf (accessed 20 June 2016) 
Fisher JD, Fisher WA (1992) Changing AIDS-risk behavior. Psychological Bulletin 111(3):455

Foot C, Gilburt H, Dunn P, Jabbal J, Seale B, Goodrich J, Buck D, Taylor J (2014) People in control of their own health and care: the state of involvement. King's Fund, London.

Forbes LJ, Ramirez AJ, Expert group on Information about Breast Screening (2014) Offering informed choice about breast screening. Journal of Medical Screening Oct 13:0969141314555350

Freedman DO, Weld LH, Kozarsky PE, Fisk T, Robins R, von Sonnenburg F, Keystone JS, Pandey P, Cetron MS (2006) Spectrum of disease and relation to place of exposure among ill returned travelers. New England Journal of Medicine 354(2):119-30

NHS Choices (2016) Lyme disease. www.nhs.uk/conditions/Lymedisease/Pages/Introduction.aspx (accessed 20 June 2016) NICE (2016) New NICE guidelines help put patients in the driving seat www.nice.org.uk/news/blog/new-nice-guidelines-help-put-patients-in-the-driving-seat (accessed 20 June 2016)

Noble LM (2014) Engaging patients in the pre-travel consultation. Practice Nursing 25(8):376-80

Noble LM (2016) The future of the doctor-patient relationship. In Brown J, Noble LM, Papageorgiou A, Kidd J (eds) Clinical communication in medicine. Wiley Blackwell, Chichester

Noble LM, Willcox A, Behrens RH (2012) Travel clinic consultation and risk assessment. Infectious Disease Clinics of North America 26(3):575-93 
Office for National Statistics (2012) Deaths registered in England and Wales 2011 www.ons.gov.uk/peoplepopulationandcommunity/birthsdeathsandmarriages/deaths/ bulletins/deathsregisteredinenglandandwalesseriesdr/2012-11-06 (accessed 20 June 2016)

Silverman J, Kurtz S, Draper J (2013) Skills for communicating with patients. Radcliffe Medical Publishing, Oxford Spiegelhalter D, Riesch H (2008) Bacon sandwiches and middle-class drinkers: the risk of communicating risk. Significance 5(1):30-3

Voumard R, Berthod D, Rambaud-Althaus C, D'Acremont V, Genton B (2015) Recommendations for malaria prevention in moderate to low risk areas: travellers' choice and risk perception. Malaria Journal 14(1):139 World Health Organization (2014) Backgrounder on WHO report on regulation of ecigarettes and similar products. www.who.int/nmh/events/2014/backgrounder-ecigarettes/en/\# (accessed 20 June 2016)

Zimmer R (2012) The pre-travel visit should start with a 'risk conversation'. Journal of Travel Medicine 19(5):277-80

Zimmermann R, Hattendorf J, Blum J, Nüesch R, Hatz C (2013) Risk perception of travelers to tropical and subtropical countries visiting a Swiss travel health center. Journal of Travel Medicine 20(1):3-10 
Figure 1. Traditional model of the pre-travel consultation

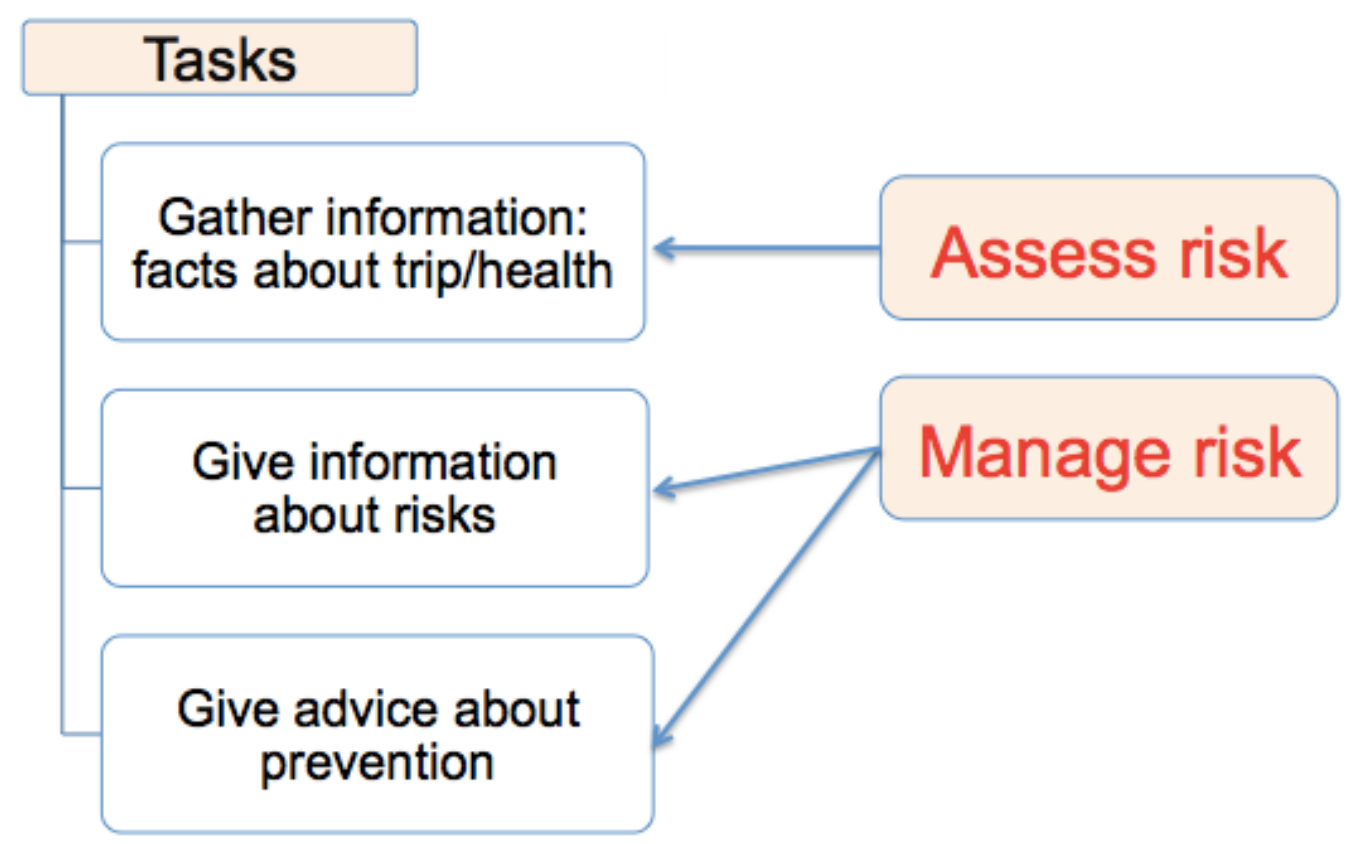


Figure 2. Information-Motivation-Behavioural Skills model (adapted from Fisher \& Fisher 1992)

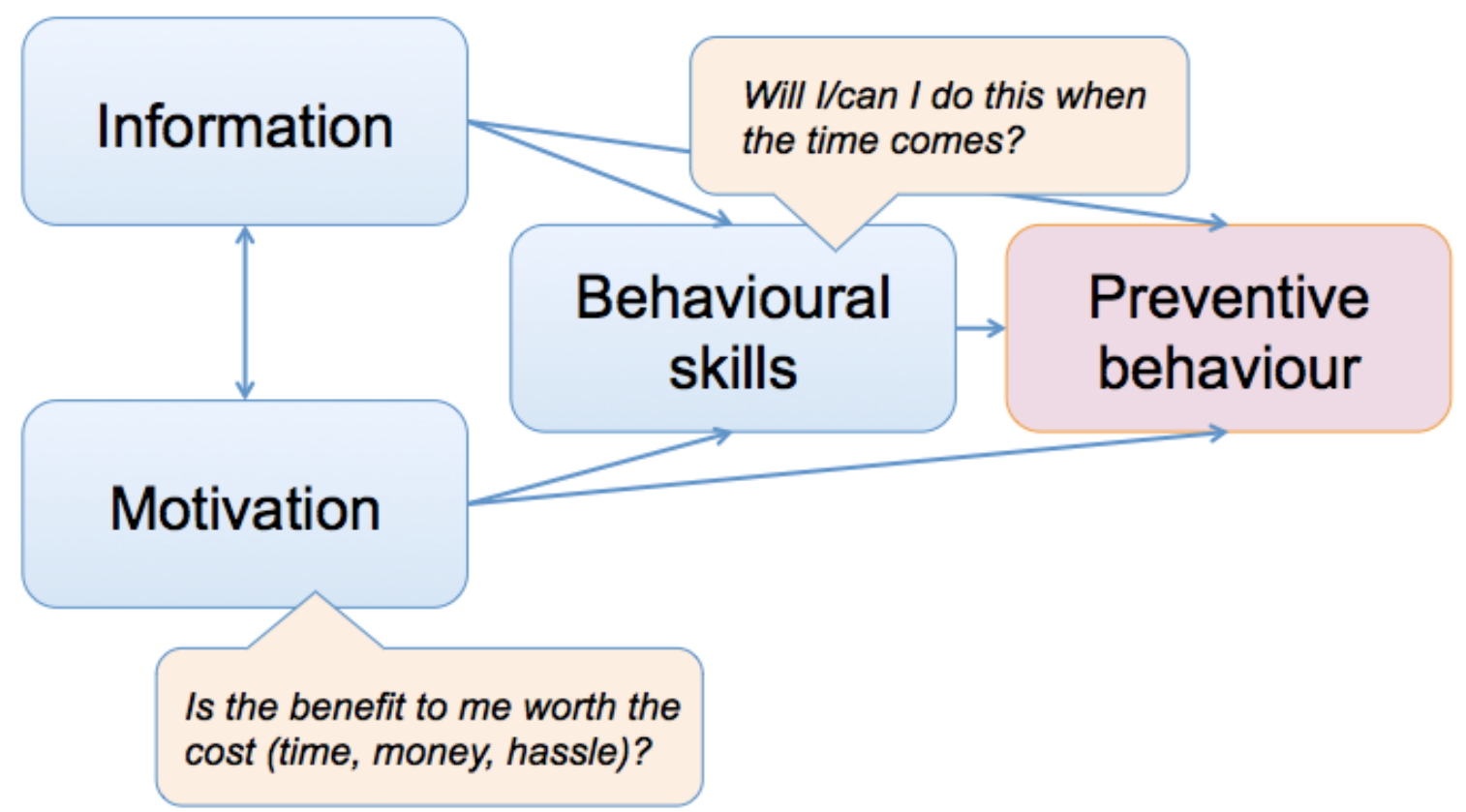


Figure 3. Patient-centred model of the pre-travel consultation

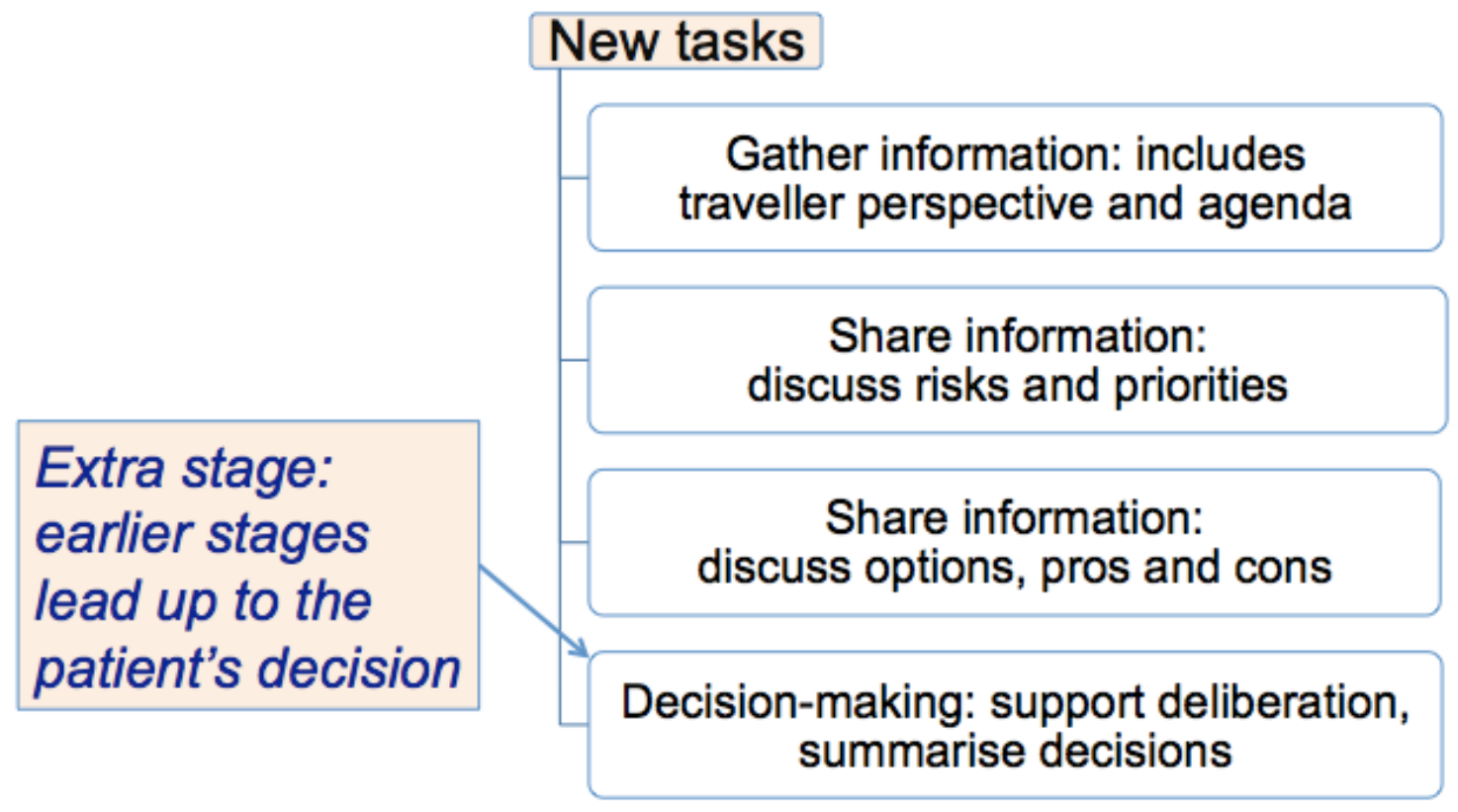


Box 1. Features of a patient-centred consultation to discuss risk

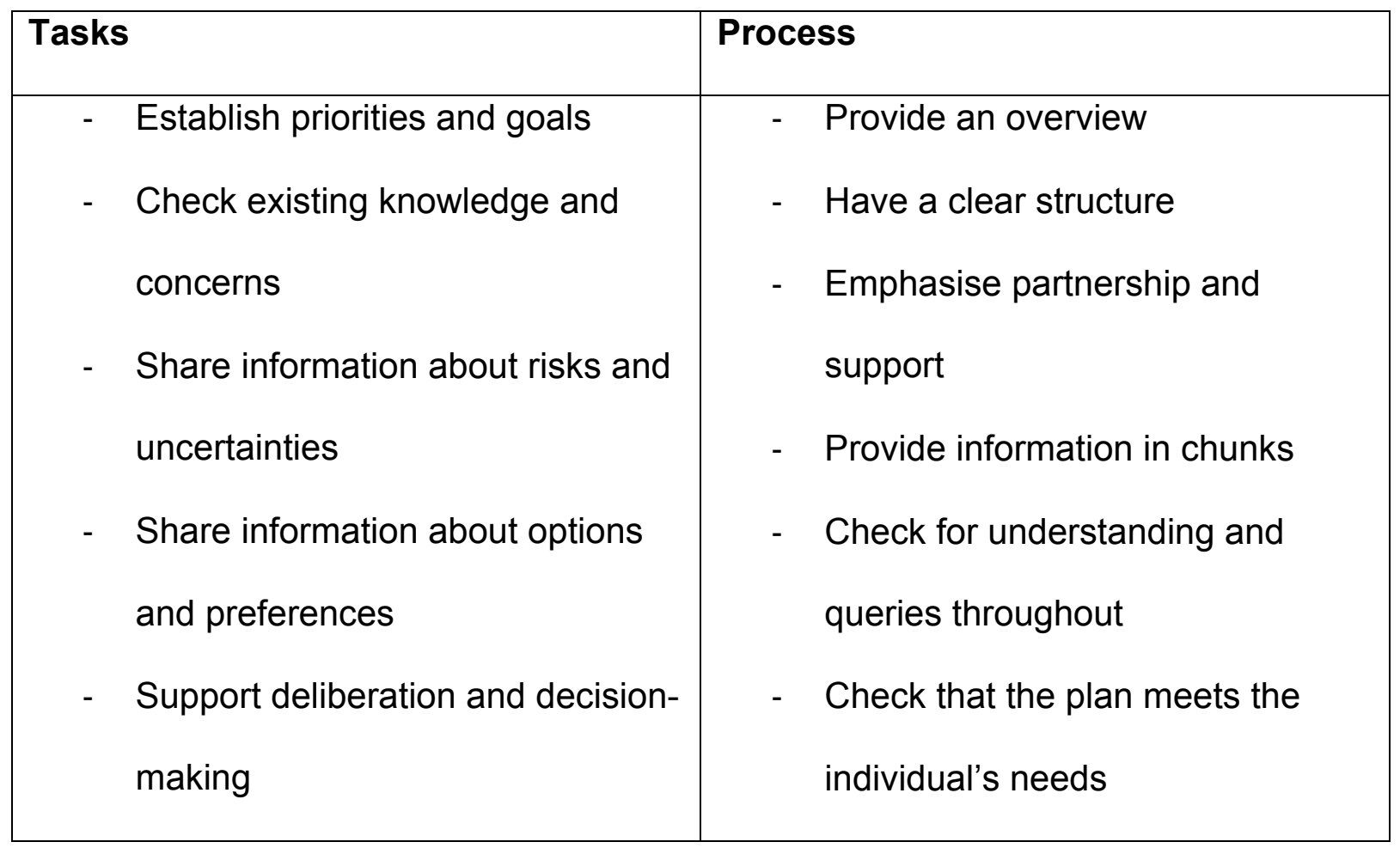

